\title{
Acute tricuspid valve obstruction following the use of tricuspid ball valve prosthesis
}

\author{
H. A. SAMAAN and R. MURALI \\ Department of Thoracic Surgery, The Royal Infirmary, Edinburgh
}

\begin{abstract}
A case is presented in which the mitral and tricuspid valves were replaced by a ball-valve prosthesis. The patient was admitted as an emergency 18 months later with the clinical picture of acute venous inflow obstruction to the heart due to tricuspid ball-valve prosthesis obstruction. Successful replacement under emergency open heart surgery, using assisted circulation, is described.
\end{abstract}

The surgical correction of advanced multiple valvular heart disease has shown the importance of correction of malfunction of the tricuspid valve (Starr, Herr, and Wood, 1966). The true incidence of significant organic or functional disease of this valve in acquired valvular lesions is difficult to establish (Braunwald, Ross, and Morrow, 1967).

Cooke and White (1941) have demonstrated involvement of the tricuspid valve in 10 to $15 \%$ of patients with rheumatic valvular disease. There are also a number of patients with mitral and aortic valve disease who suffer from functional incompetence of the tricuspid valve (Starr et al., 1964).

Correction of tricuspid valve incompetence, even if functional in the majority of cases, may be followed by gratifying results (Grondin, Lepage, Castonguay, and Meere, 1967). This is due to the fact that adequate cardiac output is essential for survival in the immediate postoperative period. Tricuspid incompetence should be corrected, especially in the presence of residual hypertension (Braunwald, Braunwald, Ross, and Morrow, 1965). Correction in selected cases by annuloplasty has its advantages, but replacement of the valve, especially if badly damaged, may be necessary (Tatooles, Braunwald, and Morrow, 1965).

Although prosthetic valve replacement has Lelped many disabled patients, these valves carry the disadvantage of thrombotic complications and other mechanical malfunctions (Herr, Starr, McCord, and Wood, 1965). The introduction of a ball-valve prosthesis by Starr and Edwards (1961) was a great advance in valve surgery. Several new valve designs for better haemodynamic function and for reduction of thrombus formation are still under trial (Davila, Amongero, Sethi, Rincon, Palmer, and Lautsch, 1966).

Anticoagulant therapy has reduced the frequency of thromboembolic complications, but clot formation on the prosthetic valve and peripheral emboli can still occur (Duvoisin, Brandenburg, and McGoon, 1957), although its incidence is less in the tricuspid area than in the mitral area. Thrombosis of a tricuspid valve prosthesis will lead to clinical signs of superior and inferior vena caval obstruction. The clinical picture of such cases has not been reported because of the difficulty in detecting malfunction of this valve in cases of multiple valve replacement. Patients with a thrombosed tricuspid valve prosthesis usually present as very ill patients, and unless they are diagnosed urgently mortality is high. We believe that this is the first clinical report of a case of thrombosed tricuspid valve prosthesis successfully replaced.

\section{CASE REPORT}

A 45-year-old housewife, with no previous history suggesting rheumatic fever, was well until 1950, when she was found, during her first pregnancy, to have mitral stenosis. After a full-term natural delivery she became progressively dyspnoeic. She had a mitral valvulotomy in 1954. She remained well until 1965 when she started to become dyspnoeic and was treated with digoxin and diuretics. In 1967 cardiac catheterization was carried out which showed evidence of mitral stenosis and incompetence with pulmonary hypertension and organic tricuspid stenosis and incompetence. In March 1968 she underwent mitra and tricuspid valve replacements with a No. 2 and No. 3 Starr-Edwards ball-valve prosthesis respectively. Her post-operative course was uneventful 
and she was sent home on anticoagulant therapy (warfarin, $6 \mathrm{mg}$. daily). She remained well until the last week of July 1969, when she started feeling tired and weak with progressive dyspnoea. She also complained of puffiness of the face and right hypochondrial aching pain associated with nausea. She was admitted to the thoracic unit as an emergency on 7 August 1969. The appearance of the patient before operation is shown (Fig. 1).

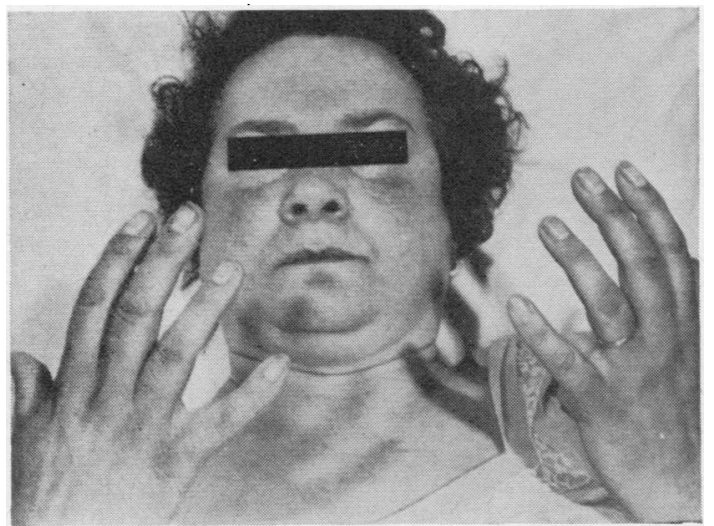

FIG. 1. The patient before operation. Note marked oedema and cyanosis of the face.
Examination revealed a fully conscious and co-operative lady with intense dyspnoea, a swollen face with cyanosis, distended neck veins and sacral oedema. None of the peripheral pulses could be felt and the blood pressure could not be recorded. The cardiac apical impulse was palpable in the sixth left intercostal space in the mid-clavicular line. On auscultation the apex rate was 110 per minute and was irregular. Only one valve click could be heard over the praecordium with maximum intensity over the apex. The lungs were clinically clear. The liver was enlarged 3 in. (76 mm.) below the costal margin in the mid-clavicular line and was markedly tender but not pulsatile. There was a moderate degree of ascites.

INVESTIGATIONS Haemoglobin 17.2 g./100 ml., PCV 53, prothrombin time 19.9 seconds. Blood urea $100 \mathrm{mg} . / 100 \mathrm{ml}$; sodium $133 \mathrm{mEq} / 1$., potassium 6.0 $\mathrm{mEq} / 1$.; bicarbonate $12 \mathrm{mEq} / 1$; chloride $93 \mathrm{mEq} / 1$; bilirubin $2.7 \mathrm{mg} . / 100 \mathrm{ml}$; serum alanine aminotransferase 700 units $/ \mathrm{ml}$; thymol turbidity 4 ; alkaline phosphatase 11 K.A. units $/ 100 \mathrm{ml}$. ; arterial pH 7.24; $\mathrm{PCO}_{2} 27 \cdot 0$; standard bicarbonate $14.2 \mathrm{mEq} / 1$; $\mathrm{O}_{2}$ saturation $88 \%$.

A chest radiograph did not reveal anything significant (Fig. 2).

In view of the critical condition of the patient, angiography was not attempted.

With the history and the findings of superior and inferior vena caval obstruction and the absence of a valve click, a pre-operative diagnosis of acute tri-

FIG. 2. Chest radiograph before operation. 


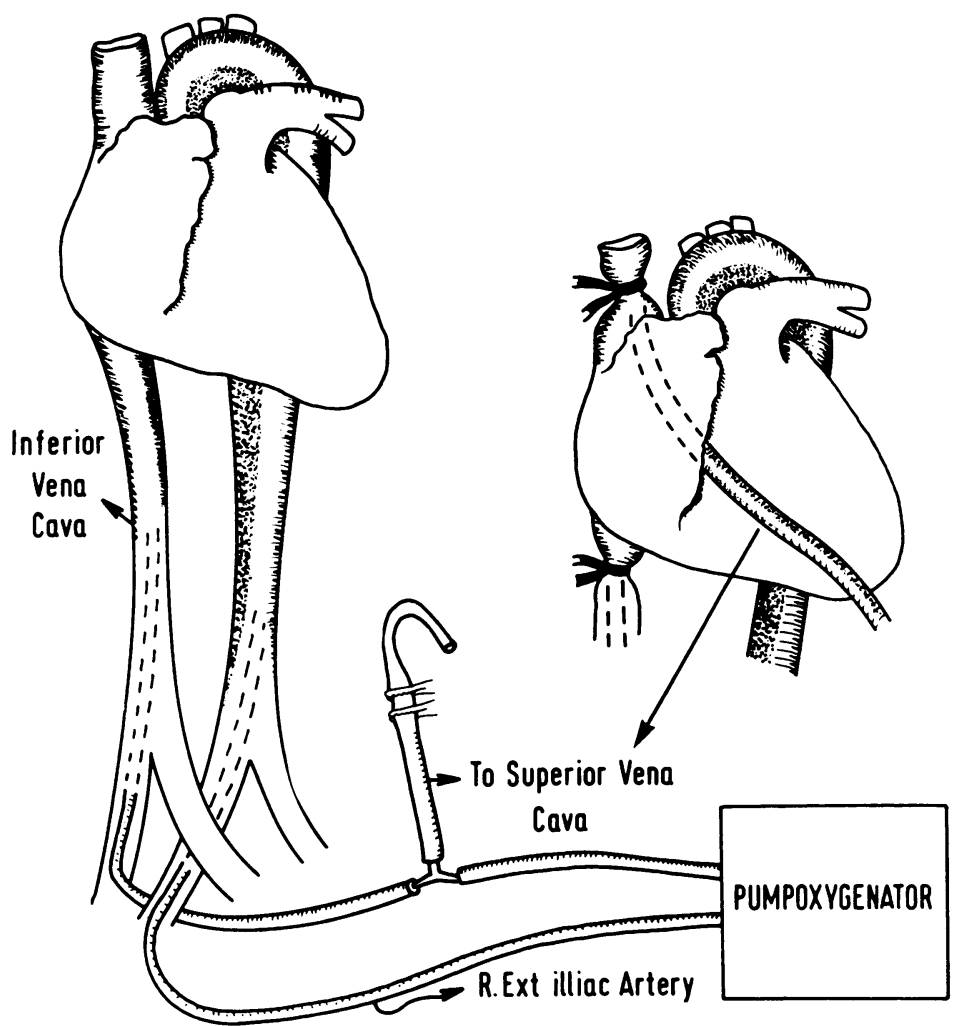

FIG. 3. Diagram of cardiac assistance. Cannulation of the inferior vena cava and the right iliac artery.

cuspid valve malfunction was made and emergency bypass surgery was decided upon.

OPERATION As an initial step, bypass (Fig. 3) was established using a large venous drainage catheter passed into the inferior vena cava through the right external iliac vein, and a perfusion cannula was placed in the rigid external iliac artery. The iliac vein was distended with blood under markedly increased pressure. Bypass was begun before the thoracotomy was made and the patient's condition immediately improved. The previous transverse thoracotomy scar was re-opened.

A superior caval cannula was then connected to the inferior caval cannula. The right atrium was opened. From the atrial aspect the Starr-Edwards prosthesis looked normal and there was no leak around it. The only abnormality was that the ball could not be moved with the finger and the valve appeared to be totally obstructed. The valve was excised. A No. 4 Starr-Edwards disc prosthesis (6500) was sutured to the tricuspid ring using a series of mattress sutures. The chest was then closed in layers after securing haemostasis.

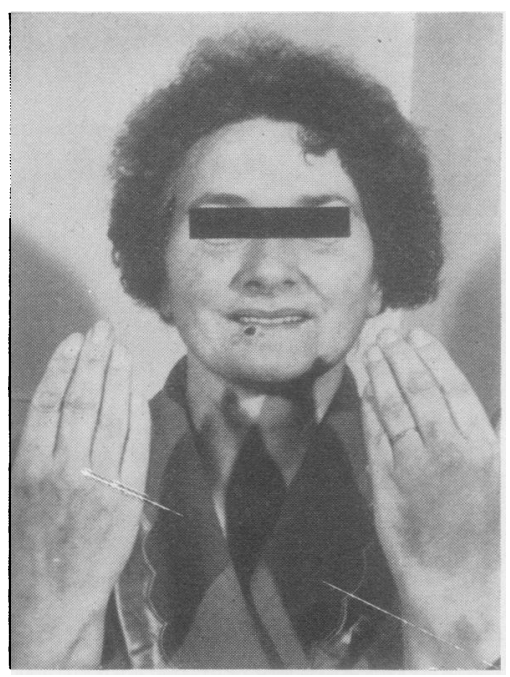

FIG. 4. The patient two weeks after operation. 


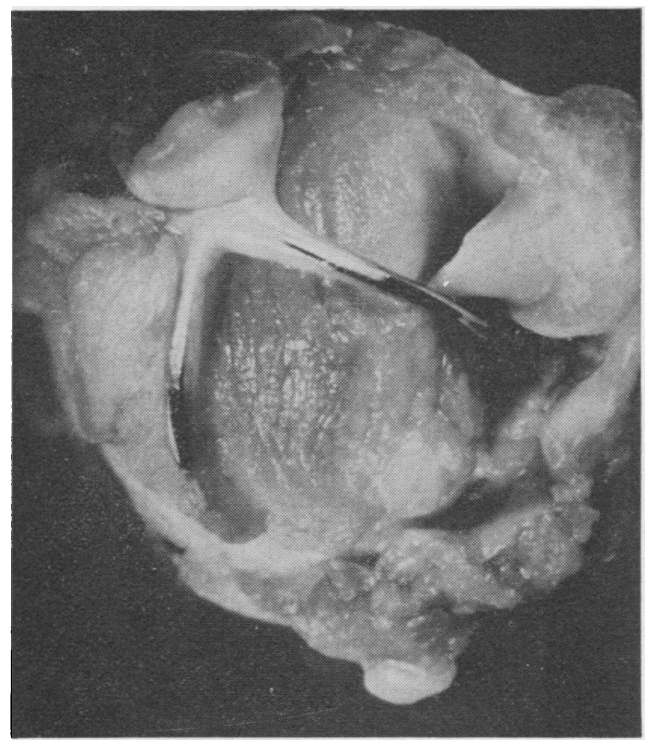

FIG. 5. Caged ball valve prosthesis seen from the ventricular side. The thrombotic material is shown adherent to the metallic structure which partially encases the struts of the cage, and the thrombus completely obstructs the ball.

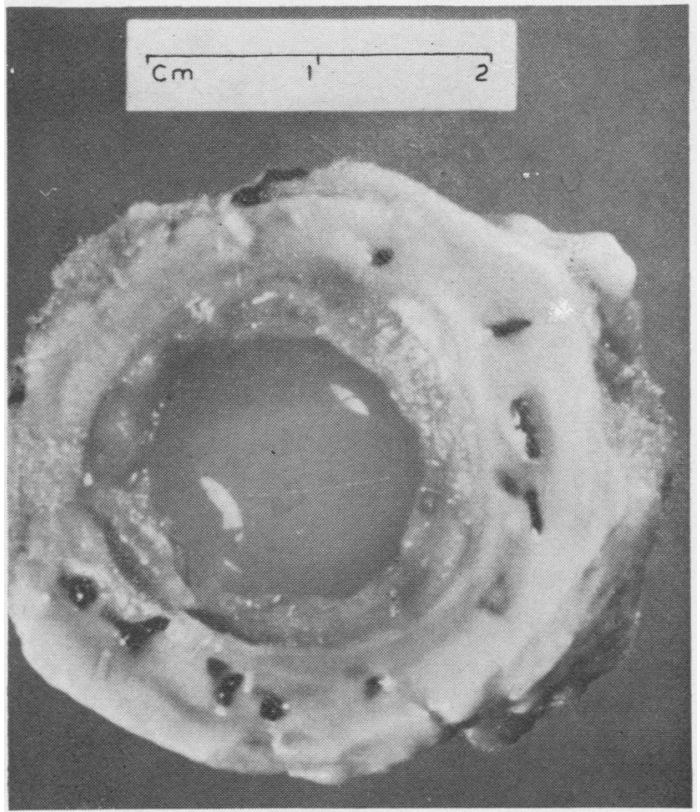

FIG. 6. The prosthesis seen from the atrial side shows firm thrombotic material between the ring and the ball. The Teflon sewing ring has been covered with endothelial-like tissue.
Post-operatively she was unconscious for about four hours, after which she improved rapidly and regained full consciousness without any neurological deficits. She required respiratory assistance from a Bird Mark 8 respirator for $\mathbf{4 8}$ hours, after which her recovery was uneventful and she was discharged. Figure 4 shows the patient two weeks after operation. Figures 5 and 6 show the excised prosthesis. From the ventricular aspect, only two tiny bits of valve strut were visible through a great spherical mass of clot covering the ball, the ring, and the cage. This mass almost filled the right ventricle; a papillary muscle was continuous with the clot and had to be divided before the prosthesis could be removed.

Microscopically the soft tissues around the excised valve consisted largely of laminated thrombus. Some areas showed early organization, as evidenced by a scanty infiltration of plump fibroblasts.

\section{DISCUSSION}

At present there is still no ideal substitute for valve replacement (Davila et al., 1966).

Promising results have been claimed for autografts and homografts as they are free from thrombotic complications and no anticoagulants are required following operation, but the technical difficulties in preparation and insertion, and their occasional failure in the long term, still restrict their widespread use (Beall, Bloodwell, Bricker, Okies, Cooley, and DeBakey, 1969).

Reports by Garamella, Lynch, Schmidt, and Jensen (1964) and Spencer, Trinkle, and Reeves (1965), amongst others, discussed the correct diagnosis in a thrombosed mitral valve prosthesis, but no reports of thrombosed tricuspid valve prosthesis have been traced. In our patient the significant rise of venous pressure in the external jugular vein, enlargement of the liver, tenderness over the hypochondrium, ascites, and, most important, absence of the click of a functioning Starr-Edwards valve made it possible to suspect the correct diagnosis in spite of the fact that the patient had both the mitral and tricuspid valves replaced by Starr-Edwards valves.

The rapid deterioration of the general condition of the patient indicated the need for emergency surgery without further confirmation by angiography. An important aspect of surgical treatment in such cases has been the use of assisted circulation by cannulation of the external iliac vein and artery, as described by Berger and Barsamian (1966), during the critical period before commencing total cardiopulmonary bypass.

Left ventricular bypass helped to relieve the venous inflow obstruction and also, according to 
Dennis, Hall, Moreno, and Senning (1962) and Cappelletti and Reynolds (1967), decreases the external work of the heart, maintains adequate blood pressure, increases oxygen tension in the myocardium, increases coronary blood flow, and protects the heart against arrhythmia, including ventricular fibrillation.

According to Najafi, Dye, Javid, Hunter, and Julian (1969), no heart patient is too ill to be operated upon if dying from an underlying surgically correctable condition, if assisted circulation is used.

We are grateful to the surgeons, anaesthetists, and cardiologists of the Cardio-thoracic Department of the Royal Infirmary of Edinburgh, especially to $\mathrm{Mr}$. A. Logan and to Mr. R. J. M. McCormack, who dealt with the emergency, and for their advice and criticism in the preparation of this paper.

\section{REFERENCES}

Beall, A. C., Bloodwell, R. D., Bricker, D. L., Okies, J. E., Cooley, D. A., and DeBakey, M. E. (1969). Prosthetic replacement of cardiac valves. Amer. J. Cardiol., 23, 250.

Berger, R. L., and Barsamian, E. M. (1966). Iliac or femoral vein-toartery total cardiopulmonary bypass. Ann. thorac. Surg., 2, 281.

Braunwald, E., Braunwald, N. S., Ross, J., and Morrow, A. G. (1965). Effects of mitral-valve replacement on the pulmonary vascular dynamics of patients with pulmonary hypertension. New Engl. J. Med., 273, 509
Braunwald, N. S., Ross, J., and Morrow, A. G. (1967). Conservative management of tricuspid regurgitation in patients undergoingmitral valve replacement. Circulation, 35, Supplement 1, p. 63.0

Cappelletti, R. R., and Reynolds, B. M. (1967). Left ventricular bypass support during surgical operations. Ann. Surg., 165, $\frac{\bar{C}}{\bar{C}}$

Cooke, W. T., and White, P. D. (1941). Tricuspid stenosis: with $\frac{\partial}{\widehat{\Phi}}$ particular reference to diagnosis and prognosis. Brit. Hearto J., 3, 147.

Davila, J. C., Amongero, F., Sethi, R. S., Rincon, N. L., Palmer, T. E., and Lautsch, E. V. (1966). The prevention of thrombosisin artificial cardiac valves. Ann. thorac. Surg., 2, 714.

Dennis, C., Hall, D. P., Moreno, J. R., and Senning, \&. (1962) Reduction of the oxygen utilization of the heart by left heart bypass. Circulat. Res., 10, 298.

Duvoisin, G. E., Brandenburg, R. O., and McGoon, D. C. (1957) Factors affecting thromboembolism associated with pros- $\frac{\overrightarrow{2}}{x}$ thetic heart valves. Circulation, 35, Supplement 1, p. 70.

Garamella, J. J., Lynch, M. F., Schmidt, W. R., and Jensen, N. K. N (1964). Fatal clotting of the Starr-Edwards mitral valve nineteen. months postoperatively. J. thorac. cardiovasc. Surg., 47, 673. $\omega$

Grondin, P., Lepage, G., Castonguay, J., and Meere, C. (1967). The tricuspid valve: a surgical challenge. J. thorac. cardiovasc. Surg., 53, 7.

Herr, R., Starr, A., McCord, C. W., and Wood, J. A. (1965). Special problems following valve replacement. Embolus, leak, infection, red cell damage. Ann. thorac. Surg., 1, 403.

Najafi, H., Dye, W. S., Javid, H., Hunter, J. A., and Julian, O. C (1969). Emergency openheart surgery for acquired heart diseases? Dis. Chest, 55, 456 .

Spencer, F. C., Trinkle, J. K., and Reeves, J. T. (1965). Successfut $\overrightarrow{0}$ replacement of a thrombosed mitral ball-valve prosthesis. J. Amer. med. Ass., 194, 1249.

Starr, A., and Edwards, M. L. (1961). Mitral replacement: the shielded ball valve prosthesis. J. thorac. cardiovasc. Surg. 42, 673.

- Herr, R., and Wood, J. (1966). Tricuspid replacement for acquired valve disease. Surg. Gynec. Obstet., 122, 1295.

- McCord, C. W., Wood, J., Herr, R., and Edwards, M. L.0 (1964). Surgery for multiple valve disease. Ann. Surg., 160, 596. 을

Tatooles, C. J., Braunwald, N. S., and Morrow, A. G. (1965). Prosthetic replacement of the tricuspid valve. Surg. Forum, 16, 171 . 